\title{
Secondary equity offerings as a leading indicator of market performance
}

\author{
Jeffrey Cain and Kellen Walsh
}

\begin{abstract}
This manuscript was prepared for ECON 4560, under the supervision of Professor Francis Tapon, Department of Economics, College of Management and Economics.
\end{abstract}

\begin{abstract}
This paper examines the perception of an imminent market downturn as a motive behind new dilutive stock issuances. Market conditions, represented by the value of the TSX composite index, are found to have a weak, yet significant relationship with the total gross proceeds of secondary offerings. The paper interprets this relationship as evidence that an influx of seasoned equity offerings is a leading indicator of a market downturn. The paper suggests that this is a result of opportunistic managers cashing in on favourable market conditions in order to insulate their capital holdings while the opportunity is still available. The paper observes a trend in which the leading secondary issuances tend to occur in two distinct peaks. The "dual peak" effect is believed to be a product of herding by managers due to relative risk sensitivity.
\end{abstract}

$\mathrm{P}$ ublicly traded companies have two major tools at hand in order to quickly raise cash, issuance of debt and issuance of further equity. Much attention has been paid to the reasons for and timing of debt and equity offerings in the capital markets. This topic has become particularly relevant recently as there have been a striking number of secondary equity offerings in the Canadian equity market. Secondary equity offerings, or SEO, are an issuance of equity that occurs after the initial public offering of a company, or their IPO. A record amount of stock had been sold on the Toronto Stock Exchange last year as of October $5^{\text {th }}, 2009$, with three months to spare before the end of the year ${ }^{1}$. But what has inspired this activity in the wake of a finance collapse? Manulife Financial CEO Donald Guloien recently announced a new stock issue that contradicts their prior promise not to dilute share prices, in order to build "the fortress level of capital" necessary to buffer against more conservative economic scenarios"2. The Manulife issue raises the suspicion that the recent influx of secondary equity offerings could be a sign that the markets have reached a peak. We hypothesize that a flood of secondary offerings by publicly traded companies indicates that these companies believe the market has reached a pinnacle and share prices will be lower in the near future.

\section{Purpose}

The purpose of this paper is to test the hypothesis that the issuance of secondary offerings is influenced by the perception of an imminent dip in the market. This is a timely and relevant topic due to the recent influx of seasoned equity offerings in the Canadian market. The hypothesis will be tested using and manipulating time series data and employing regression analysis in order to seek out a correlation between the value of secondary offerings issued and a delayed decrease in the value of the TSX market index.

\section{BACKGROUND}

To our knowledge, there are currently no studies pertaining to the relation of the issuance of secondary equity offerings in Canada and the performance of the market index. Secondary equity offerings in this paper pertain to secondary offerings that increase the amount of outstanding shares the issuing company has. This is the first comprehensive study of this sort; however multiple authors have dissected the motives for firms to issue new stock. DeAngelo, et al., take a similar stance on the issue, asserting that market conditions influence a firm's decision to issue new stock; however it is not the driving reason behind the issuance. ${ }^{3}$ Kim and Weisbach had similar findings with respect to market conditions in their paper, Motivation for Public Equity Offers, which contends that the firm's Tobin's $q$ relationship is the more telling statistic, however they concede that market conditions come into play. ${ }^{4}$ However, this paper analyzes SEO's which are not dilutive in nature. In LongRun Seasoned Equity Offering Returns, Pontiff and Schill state that firms issue secondary offerings when their stock is overpriced. ${ }^{5}$ Also, there has recently been much speculation in the financial news as to the reasons for the abundance of secondary offerings in the Canadian marketplace this year.

Exploitation of market timing may be a secondary reason for the issuance of SEO's. ${ }^{3}$ The paper states that the primary reason for most SEO's is the threat of a near term 
liquidity squeeze. According to the study, " $62.6 \%$ of issuers would have insufficient cash to implement their chosen operating and non-SEO financing decisions the year after the SEO"3. Other evidence in the paper that contradicts the market timing theory is that a swing in future market returns of $150 \%$ increases the probability of an SEO by only $1 \%^{3}$. In essence, the paper finds that a large number of firms do not issue stock during a time when it is believed the value of the firm's stock is hitting a peak. This contradicts the theory that market timing is the motivating force behind SEOs. The paper finds that due to the operations of the companies issuing the SEO, 74.2\% would run out of cash by the end of the following year, more evidence that liquidity squeeze could be the driving force for most SEO's. ${ }^{3}$ The work of DeAngelo et al, while related to our work, studies whether SEO's are driven by the firm's value, or the firm's need for cash, not the firm's perception of the state of the market. Therefore, while this paper offers an adjacent look to our study, it tests the market timing theory using the future returns of the company, not the future returns of the market as a whole.

Next, Kim and Weisbach examine the reasons behind the timing of equity offerings. ${ }^{4}$ The paper studied both initial public offerings as well as 12373 secondary offerings from 38 countries between 1990 and 2003. They find that firms issue public offerings in order to raise money for investment, however they also found that "market timing as well as investment financing is a motivation for equity offers" $"$. The author's research is "consistent with the view in which equity offers are sometimes used to finance investment, and sometimes, when a firm is valued very highly by the market, to exploit the high valuation both for the shareholders' and managers' benefits"4. They also found that the fraction of the amount of money raised by public offerings held by the firm increase with an increase in Tobin's $q$., which is to say that firms are prone to raising capital through market offerings primarily to exploit favourable market conditions. Once again, the work of Weisbach and Kim seems to focus more on the stock performance of the company in question rather than the market as a whole as the motive for new equity issues. This differs from our paper, which attempts to infer a relationship between secondary offerings and market trends.

Pontiff and Schill also direct their attention to favourable valuations of the firm's stock rather than the decisions facing a firm within the context of the market. ${ }^{5}$ They postulate that the motive for issuing a secondary equity offering is based on asymmetric information and whether a firm believes their stock is overpriced. Pontiff and Schill state that a firm will issue a secondary offering when their stock is priced higher than the value the firm would place upon their stock. ${ }^{5}$

This topic has been very apparent in recent news. In October 2009, the Globe and Mail reported that as the market has climbed out of the recession, equity offerings have increased dramatically. In fact, in the past six months,
Canadian companies have raised $\$ 20.4$ billion, and over the year a record $\$ 35.5$ billion has been amassed by Canadian companies. ${ }^{6}$ In particular, the resource sector has been particularly active in issuing seasoned equity offerings. During the financial crisis, cash dried up quickly for companies in the resource market, and they are currently taking advantage of the recovering market. ${ }^{7}$ The largest sale of equity ever was recorded in the resource sector by Barrick Gold Corp., with an issuance of $\$ 4$ billion worth of Barrick stock. ${ }^{6}$

Through review of past literature, it is apparent that most studies of the reasons for secondary offerings examine the performance of individual stocks and the needs of the separate entities. While these studies are related, we wish to see if there is a relation between the issuance of seasoned offerings, and the performance of the market as a whole. Due to the current rise in the TSX, firm's have been issuing equity at a record rate and therefore this question is very relevant.

\section{DATA}

This paper uses monthly time series data of the Toronto Stock Exchange Composite Index dating back to January 1993 as well as data about each of the over twelve thousand secondary equity offerings made within Canada since January 1993 from FPInfomart. The secondary offerings observed were all new shares issued, not the resale of existing shares. The sample size is sufficient to draw reliable conclusions, as the dataset is completely inclusive of all secondary offerings in the last 16 years. This time period includes several significant equity market occurrences such as the dot-com bubble burst and the recent financial collapse. The raw data contained information regarding the issuing firm, whether the offering was debt or equity, the amount of shares issued, the price per share, the gross proceeds, total proceeds and the date at which the secondary offering was issued. First the data was revised to contain only the secondary equity offerings. Next, the data was organized by issue date and grouped by month, which provided the data for monthly gross proceeds, monthly shares issued, number of offerings per month and the average offering value per month. The time series data of the Toronto Stock Exchange Composite index was similarly organized by monthly value in order to seek the correlation between the secondary equity offering information and the returns of the index. An additional data set was assembled in which outliers were removed in order to create a more consistent time series. We believe this may increase the reliability of the data as the Toronto Stock Exchange consists of many small and few large companies. Therefore we thought large issues by the few large companies might distort our results. Additionally, to overcome the observed in the monthly figures volatility, we smoothed the results by organizing the data into quarters. 


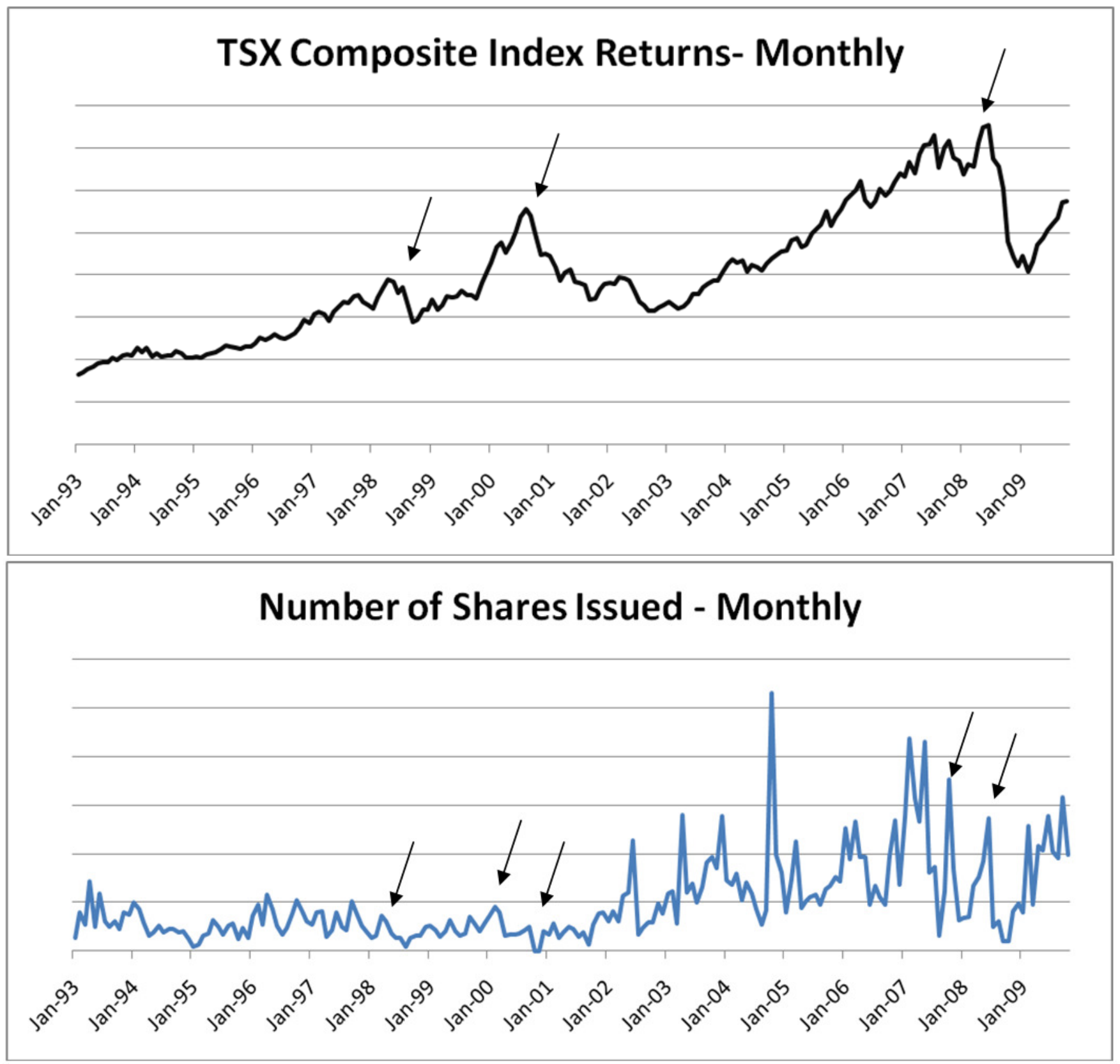

Figure 1 with peaks identified by arrows.

\section{Methodology}

\section{Average Secondary Issue Value:}

Shows how substantial the offering of each firm is on average. If it is significantly large prior to a peak it shows evidence of an attempt by the issuing firm to capitalize on current market conditions before a perceived market drop.

\section{Monthly Total Gross Proceeds:}

MTGP is expected to be the most telling variable. The times series of MTGP is hypothesized to show whether a correlation exists between the two datasets as well as give a better indication of how long the expected lag period is.

\section{Number of Secondary Offerings Per Month:}

Represents the number of firms who issued secondary offerings during a given month. If this value correlates with the times series of the TSX Composite, then there is reason to believe that firms are expecting a drop in the market's value and the secondary offering is an attempt to cash in on fleeting opportunities. This will show how prevalent the view 
is that the mark is to fall and firms' ability to predict this downturn.

\section{Monthly Number of Shares Issued:}

This variable is a mechanism for determining a trend that will support the hypothesis, however is this variable is expected to be less significant than the other variables analyzed.

\section{TSX Composite Index:}

The TSX Composite index is used as a reference point for the other variables in question to be compared to. Trends in the TSX represent the state of the Canadian equity market as a whole, from which inferences can be made.

We then used statistical software, STATA, to analyze the variables using a linear regression analysis and a correlation test. In our regression analyses, the dependent variable was the various ways we measured secondary offerings, and the independent variable was the TSX composite index. We tested the data using lags ranging from one to ten months in order to better test our hypothesis that secondary offerings indicate a future dip in the market.

\section{TIME SERIES ObSERVATIONS}

In order to determine the relationship between the TSX composite index and our numerous variables of interest we visually analyzed the time series graphs of each individual variable and compared the movement of the variables to the movement of the TSX. We chose three points in time where the TSX was peaking prior to a significant downturn. Next, we looked at how each variable performed prior to the specified date. The dates on the graphs that we chose were May 1998, July 2000, and May 2008. These dates represent peaks in the TSX composite index prior to the Asian currency crisis, the dot-com bubble bursting and the current recession respectively.

The first variable investigated was the total number of shares issued per month. According to Figure 1, there was a local maximum of shares issued in March of 1998. This peak predates the peak in the TSX composite index in July 1998 by about two months and could be an indicator that firms were cashing because they foresaw an imminent drop in the market. In February 2000, shares issued again reached a large pinnacle, which was followed by a drop off. However, shares again began to climb at a moderate pace until the dotcom bubble burst and at that point almost no shares were being issued. The peak in February 2000 could be because some people believed the "good times" were about to end, however many people appeared to be taken by surprise as shown by the continuance of shares being issued up until
July 2000. The current recession is very evident in the TSX composite index in Figure 1. The market peaked before the recession in May 2008. There was a peak in shares issued in October of 2007, seven months prior to the beginning of the recession. However, shares issued began climbing again in January and peaking in June 2008. There appears to be "dual peaks" in shares issued prior to the market crash. This "dual peak" effect could be due to some managers predicting the market drop off earlier than others, and cashing in sooner as a result of their sensitivity to risk. Therefore, this "dual peak" effect could be due to managers being risk seeking, and will wait until the last second to cash in before a market dip, or risk averse and will try to increase liquidity well before the market declines in value in order to protect the firm. In summation, there appears to be a weak relationship between the number of shares issued and a lagged peak in the TSX composite index value, however this correlation relies on many inferences. There also appears to be a "dual peak" effect, which may be explained by the variability of risk sensitivity of managers.

The next variable our study analyzed was total gross proceeds from secondary equity offerings, per month. Figure 2 depicts total gross proceeds as well as the TSX composite index on time series graphs. The relationship between gross proceeds and the TSX composite index was difficult to decipher as the gross proceeds variable was so volatile which is evident in Figure 2. There was a peak in March 1998, possibly showing firms cashing in prior to the TSX peak in May of 1998. The "dual peak" effect once again seems present as there is another peak earlier that occurred in October of 1997. Prior to the dot com bubble burst in 2000, the gross proceeds variable displayed many peaks. The largest peak appears to be the year before in May of 1999, however we believe this to be most likely related to something other than manager's predicting a large dip in the market. Also, preceding the current recession were two peaks, in January and May of 2008. The "dual peak" effect that was evident in the shares issued graph is once again evident. The peak in January 2008 was actually during a small dip in the TSX. We hypothesize that this may be due to companies anticipating a much further drop and trying to cash in or increase liquidity. The climax of shares issued in May 2008 may reflect some managers being more risk taking and waiting until the last second to cash in on a market peak. Also, some managers may be taken by surprise by the market crash, suggesting managers have imperfect information regarding market performance. To conclude, again the "dual peak" effect was evident in our graph. The visual correlations seem weak at best again, however the volatility of gross proceeds make it tough to consider as an indicator of the direction the market may be heading. 

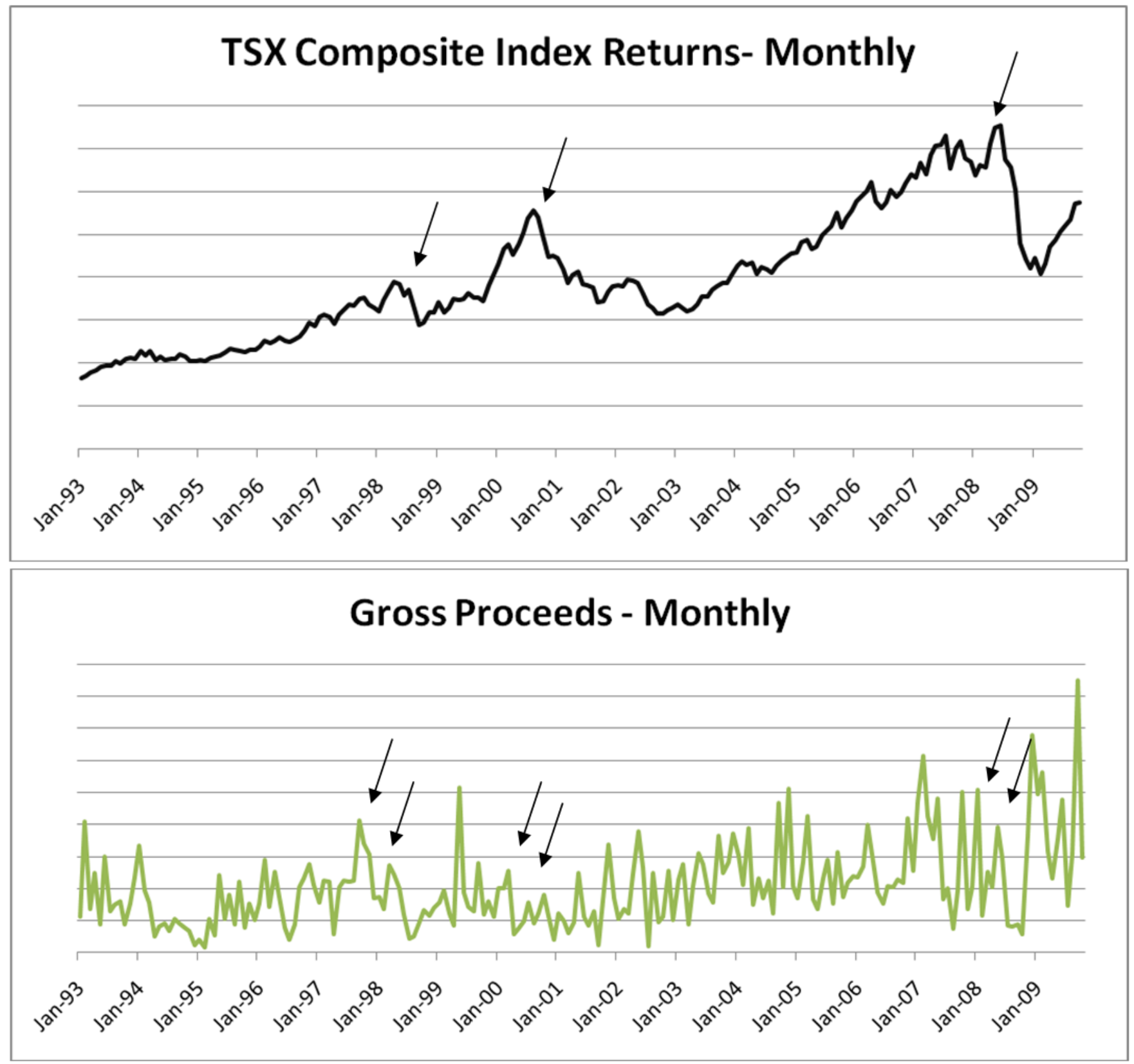

Figure 2 with peaks identified by arrows.

Total number of offerings during each month was the next variable analyzed. Figure 3 contains time series graphs of total number offerings and the TSX composite index. The peak in May 1998 of the TSX is preceded by a peak of total number of offers in March 1998. There appears to be no double peak present, however the correlation seems distinct and shows a lag of two to three months between when the number of offerings peaked when the market took a dive. There was a large peak in number of offerings in February 2000, and a small peak in June of the same year. This somewhat reflects the "dual peak" effect our other variables displayed, and also presents a roughly seven month lag from where number of offerings first peaked and where the market began plummeting after July of 2000. Previous to the most recent market crash, there were many peaks in total number of offerings per month. In fact, in June 2008, just after the market began its decline, the number of offerings peaked; indicating firms may have been taken by surprise at the sudden decline in the market. The total number of offerings per month showed, once again, a weak correlation with a delayed peak in the value of the market index. This may show that sometimes firms are able to cash in on peaks, but 

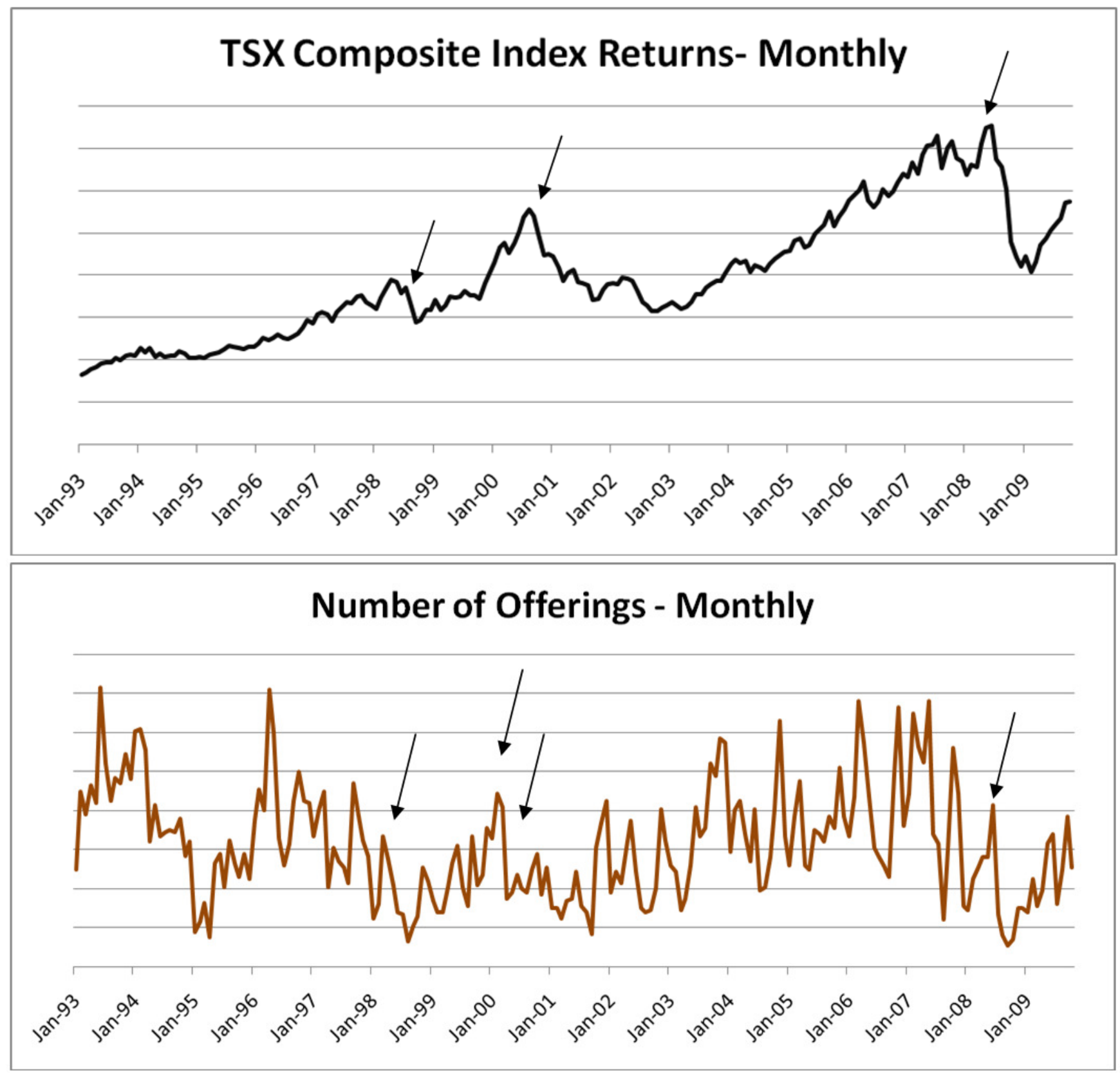

Figure 3 with peaks identified by arrows.

other times are surprised by the market decline. Also, number of offerings may peak due to a "herding" effect; as managers see other firms issuing equity on the hunch that the market may be peaking, they follow suit. However, as indicated by the situations where firms seem to be taken by surprise when the market declines, managers do not have all the information to be able to consistently correctly predict how the market will perform.

Our last variable tested was average secondary issue value. Figure 4 depicts this variable on a time series graph below the graph of the TSX composite index. As demonstrated by the graph, there is a peak in January 1998, as well as in May 1998 of average secondary values. These peaks predate the apex reached by the TSX composite index in May of 1998. This could be construed as what we have come to know as a double peak. However, the peak in May 1998 of average secondary issue value is more likely a result of a sharp decrease in average secondary issue value following this month. Before the dot com bubble burst after July of 2000, two small peaks appeared; in March and July of 2000. Once again, the peak in July of 2000 was probably due to the market declining in value. Lastly, a double peak of 


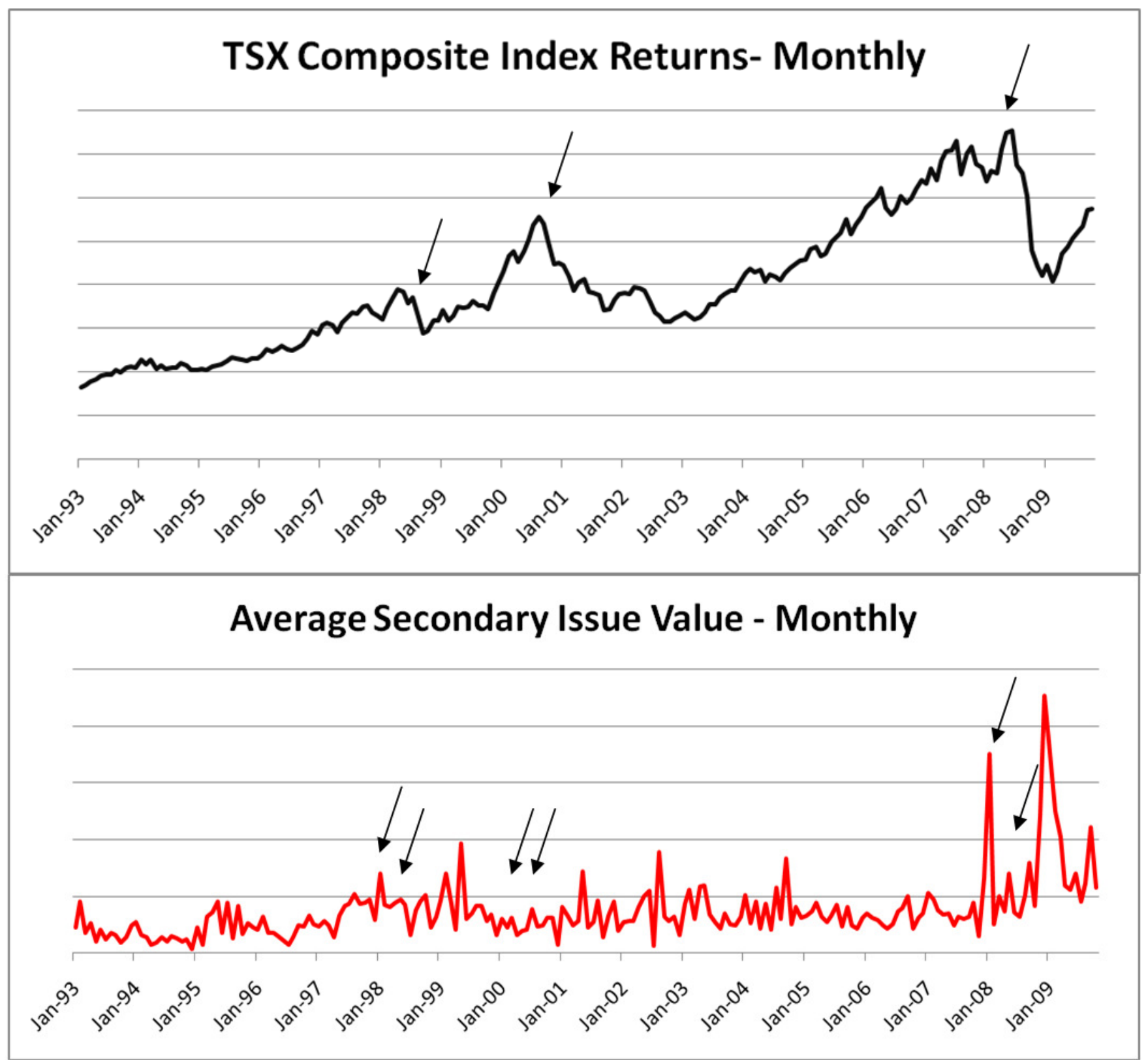

Figure 4 with peak dates identified by arrows.

secondary issue value is present before the recent financial collapse. These peaks occur in January 2008 and May 2008. However, from January 2008 onwards the average value of secondary offerings becomes increasingly volatile. This may be a reflection of desperation on the part of managers to raise capital in order to weather upcoming poor market conditions. Although a "dual peak" effect appears in this variable, the second peak is most likely due to the market decline and the nature of the variable.

We subsequently smoothed our raw data by grouping the months into quarters. The reason for this was to remove some of the volatility from the time series graphs and provide a more general picture of the movements of our variables compared to the movements of the TSX composite index.

The inferences from the original monthly data remain the same; however the quarterly data did remove some of the smaller dips and peaks that made the time series graphs difficult to decipher. We expected our observations to remain the same, despite the smoothing, as we analyzed very significant peaks and troughs in our variables.

The time series graphs provided our study with many interesting observations. First, it appears that maximum values occur in the seasoned equity offering variables in periods just prior to a market peak, which we postulate to be indicators of a future market peak. The secondary offering 
variables were much more volatile than the TSX composite index value. This volatility was to be expected, as managers will never be able to always cash in on market peaks at the ideal time due to imperfect information. There are also many reasons for which a firm will make a secondary offering in addition to the market timing examined in this paper. Another trend to be noted was how there were often two sharp peaks prior to a significant market occurrence. This effect may perhaps illustrate a herding tendency by managers of varying degrees of risk sensitivity. More specifically, riskaverse managers will cash in much earlier on an anticipated peak in the market, and more risky managers will wait until the last second to issue equity. Some may even be caught by surprise by a sudden market decline. We termed the market's suspected inherent ability to group firms into two categories of risk sensitivity the "dual peak" effect. Lastly, the volatility of our variables could be due to a "herding" effect as a future dive by the market becomes a common expectation and managers follow each other to cash in on the peak in the market at the same time.

\section{REGRESSION ANALYSIS}

The regression analysis has two primary objectives; to test the strength of the relationship between the measures of seasoned equity offerings and to determine what is the appropriate lead-time between the issue of a secondary offering and the corresponding financial event. In order to determine the lead-time, we regressed our previously described variables against the TSX composite index with various lags.

The first measure of secondary equity offerings examined was the number of shares issued. The regression analysis using the non-lagged TSX as the independent variable yielded an $\mathrm{R}^{2}$ value of .2737 and a t-statistic of 8.68, which indicates that the value of the TSX composite has a significant impact over the number of shares issued. In order to fulfill the second objective of the regression analysis, the same regression was run using lags ranging from one to ten months on the TSX. It is understood that the actual effect is one of a lead by the secondary offering variables; however it is simpler to impose a lag on the TSX for regression analysis, which has the same results as a lead. When testing for a lead, it is observed that both the $\mathrm{R}^{2}$ and the t-statistic are increasing as the lag increases, until the two respective statistics hit a maximum at the four month mark. For a four month lag, the $\mathrm{R}^{2}$ value is .2957 and the t-statistic is 9.07. According to the regression, the appropriate lag between a peak in number of shares issued and a pinnacle of the value of the TSX composite index is four months. In addition, the level of the TSX Composite Index is significant in terms of its effect on the number of shares issued.

Next, a regression using the gross monthly proceeds of secondary equity offerings as the dependent variable and the TSX composite index price as the independent variable was run. The results of the regression were less striking than that of the monthly number of shares issued regression. However, an $\mathrm{R}^{2}$ value of .1764 and a t-statistic of 6.43 were supportive of our hypotheses of a lagged peak in the TSX. In addition, through the results of the regression analysis, it was found that the level of the TSX composite index has an effect on gross proceeds.

The variables of number of secondary issues per month and the average secondary issue value were not found to be significant through regression analysis. The results of the regression analysis improved for each variable as a lag was imposed on the TSX data, which supports the theory that there is a lead phenomenon of secondary issues prior to a significant market occurrence. The resultant statistics from these two regressions were not sufficient to draw any inference from.

The secondary offering variables were regressed against two alternative TSX variables in which a logarithm of the TSX and the percent change in the TSX price index were used as the independent variables. The results from these regressions were found to be unsupportive of the aforementioned hypotheses, yielding both poor $\mathrm{R}^{2}$ and $\mathrm{t}-$ statistic values as can be seen in the appendix.

Another series of regressions were performed with the data arranged by quarter. This data was less volatile and thus, predicted to provide a cleaner regression analysis. The results of the quarterly regression analysis further supports the findings from the regression analysis performed using monthly data.

Prior to running the regression analysis, gross proceeds were identified to be the most theoretically significant variable because of its ability to reflect the amount of secondary offerings issued and the size of them, which are both important considerations from which to draw inferences from regarding the timing of secondary offerings. The validity of this assumption was solidified by a collection of encouraging $\mathrm{R}^{2}$ and t-statistics, which reached a peak at .3205 and 5.49 respectively. Another important point to note is that the explanatory power of the variable reached its peak values for gross quarterly proceeds during the second quarter, which supports the notion of a lead effect being present. The significance of the independent variable, the TSX composite index, also reached its peak value at this point in time, illustrated by the t-statistic. These findings reinforce the belief that the lead window is approximately four to eight months prior to a market occurrence.

In the previous regression analysis, the best $\mathrm{R}^{2}$ value was experienced from the variable that represented the number of shares issued per month. The quarterly regression analysis saw these numbers rise marginally, implying that the quarterly data better explains the relationship between secondary equity offerings and the TSX Composite Index. As with the prior regressions, the explanatory statistics rose as a greater lag was imposed onto the TSX variable, returning maximum values at the three-quarter mark. This is consistent with the lag observed in the previous regression, where it was found that the average lead window between a 


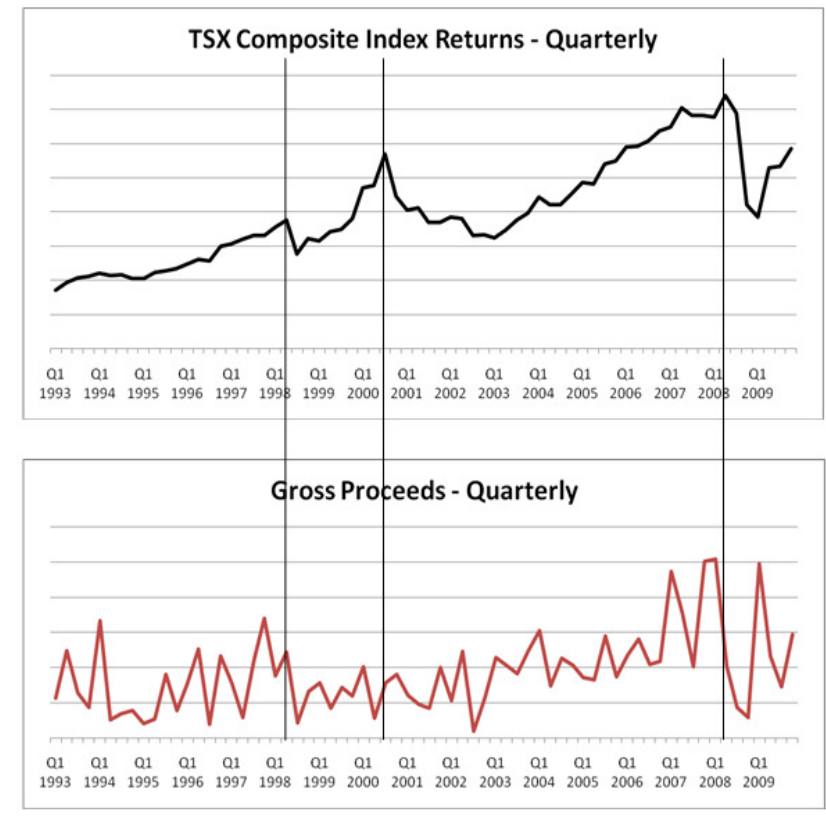

Figure 5: Quarterly TSX composite index return and gross proceeds

peak in the secondary equity offering variable and the TSX was within four to eight months.

In the quarterly regression analysis, the gross proceeds and the monthly number of shares issued were found to be the most compatible with regression analysis, which allowed the researchers to propose that a reliable relationship occurs between the timing of seasoned equity offerings and the price of the Toronto Stock Exchange Composite Index. This relationship is said to manifest itself during a lead window of four to eight months prior to when the price level peaks.

The regression analysis was supportive of the notion that the number of shares issued as well as the gross proceeds accumulated from secondary offerings each month were significantly affected by changed in the TSX composite index price as well as the fact that there is a lead effect in the issuance of secondary offerings prior to a change in the equity market.

\section{Conclusions}

Previous literature on secondary equity offerings has covered individual stock returns as the motive for issuing secondary equity; however no prior studies have examined the relationship between the market level and secondary offerings as our paper has. Our findings are consistent with the findings of Kim, Wiesbach (2005), DeAngelo, Deangelo, Stulz (2007), Pontiff and Schill (2001), in that the results reaffirm the notion that market timing is a factor in the firm's decision to issue new equity. Our results differ from the related literature in the way that we feel that market conditions, rather than just the valuation of the firm itself play into the decision of the firm to issue new equity. Our

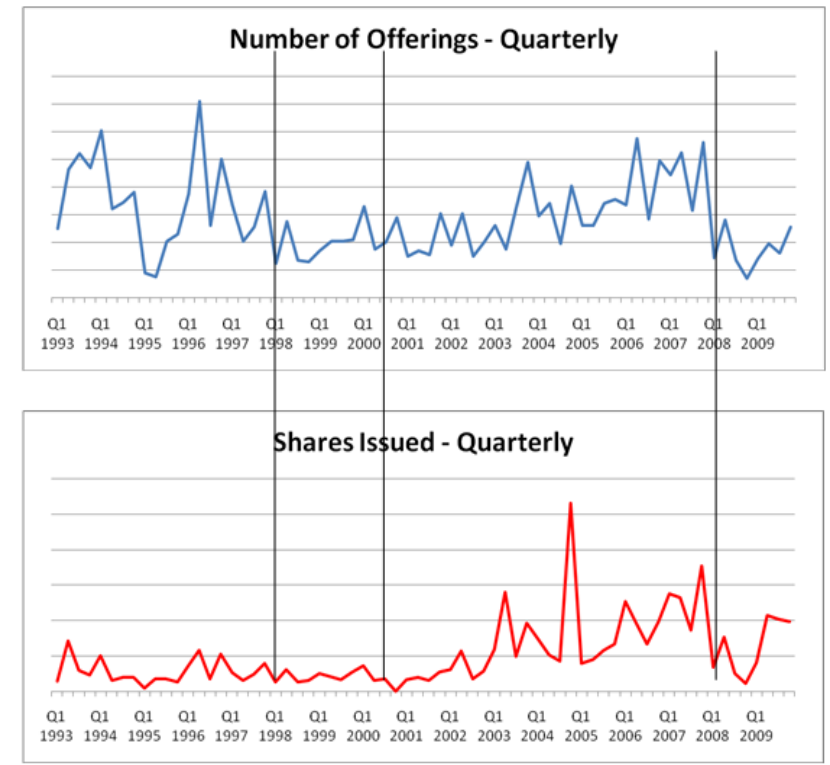

Figure 6: Quarterly number of offerings and shares issued

data is evidence that firms have a tendency to cash in on favourable market levels before an expected drop.

This study has found that a large incursion of secondary offerings serve as an ex ante indicator that the market may peak in the future. The ex-ante indicator concept can be seen in the time series analysis which features consistent trends of secondary offerings peaking prior to a significant market descent with various lags. Through regression analysis we found that on average the most reliable lead window for secondary offering issuance is four to eight months prior to the market drop.

The study postulates that large companies who issue the greatest amount of equity may be better at forecasting market trends, as when the gross proceeds were adjusted to account for outliers by removing the largest equity offerings, the accuracy of the regression was diminished.

Findings in our times series graph analysis arouse the suspicion that management risk aversion may lead to a dual peak in secondary issuance preceding a drop in the market. We feel that the risk sensitivity dispersion teamed with the herding effect creates successive peaks in secondary offerings in which risk averse managers issue secondary offerings well before the market falls, while risk-loving managers are more willing to wait until closer to the dropoff.

Our data weakly supports our hypothesis, which makes sense because managers are limited in their ability to predict market conditions and there are other reasons as to why a company will make a seasoned equity offering, for example, investment opportunity and the need for liquidity. In conclusion, market timing is tied into the firm's decision to issue new equity; however it is merely a consideration rather than the driving force behind the decision. 


\section{ACKNOWLEDGMENTS}

The authors wish to thank Yvonne Yip of the FPInfomart for facilitating the acquisition of the dataset used in the study. Such a contribution was crucial to the success of the paper. We would also like to thank our professor, Francis Tapon, for his invaluable guidance throughout the entire process of constructing the study. We would also like to acknowledge that the original concept of examining the correlation between secondary equity offerings and the equity market was devised by and brough to our attention by Professor Tapon.

\section{REFERENCES}

1. Steve Ladurentaye. (October 5, 2009). Cash-hungry companies push stock sales to record. The Globe and Mail.
2. October 20, 2009. Manulife Stock Plunges After $\$ 2.3$ Billion Issue. The Globe and Mail.

3. DeAngelo, DeAngelo and Stulz. (2007). Fundamentals, Market Timing and Seasoned Equity Offerings.

National Bureau of Economic Research.

4. Woojin Kim and Michael S. Weisbach. 2007. Motivation for Public Equity Offers: An international Perspective. Journal of Financial Economics, 87(2), pp. 281-307.

5. Jeffrey Pontiff and Michael J. Schill. (2001) Long-Run Seasoned Equity Offering Returns: Data Snooping, Model Misspecification, or Mispricing? Working paper, A Costly Arbitrage Approach, Boston College.

6. October 20, 2009. Canadian Equity Offerings Set Record. The Globe and Mail.

7. November 4, 2009. Toronto-listed Miners Issue Stock at Record Price. The Globe and Mail. 